\title{
Is ST-segment elevation myocardial infarction (STEMI) always STEMI? Case report of a rare cause of an electric storm
}

\author{
Joanna Wojtasik-Bakalarz ${ }^{1}$, Agata Krawczyk-Ozog ${ }^{2}$, Salech Arif ${ }^{1}$, Maciej Bagienski ${ }^{1}$, Barbara Zawislak ${ }^{1}$ \\ ${ }^{1}$ Intensive Cardiac Care Unit, University Hospital, Jagiellonian University, Krakow, Poland \\ ${ }^{2}$ Cardiology and Cardiovascular Intervention Department, University Hospital, Jagiellonian University, Krakow, Poland
}

Adv Interv Cardiol 2020; 16, 4 (62): 474-476

DOI: https://doi.org/10.5114/aic.2020.101774

\section{Case report}

A 60-year-old woman was admitted to the Catheterization Laboratory of the Cardiology Department with acute coronary syndrome with ST segment elevation of the anterior wall (STEMI anterior) complicated by sudden cardiac arrest due to ventricular tachycardia (VT). The day before the patient was admitted to the Department of Metabolic Diseases of our hospital due to dehydration (diarrhea), hypoglycemia and delirium. The patient's previous medical history included chronic coronary syndrome, percutaneous coronary intervention of right coronary artery, circumflex artery and left anterior descending artery in 2012 and thyroidectomy due to papillary thyroid cancer in 2001. Additionally the patient had a history of hypercholesterolemia, hypertension, epilepsy, prediabetic state, alcohol dependency syndrome and depression.

At admission, the patient was conscious with disorientation and distorted perception, without chest pain or dyspnea. ST segment elevation in precordial leads and prolonged QT interval were present in ECG (Figure $1 \mathrm{~A}$ ). Urgent angiography revealed no obstructive lesion in coronary arteries and a good outcome of previous interventions (TIMI 3 in all coronary arteries). After angiography the patient presented persistent hypotension requiring vasopressors (norepinephrine in dose $0.1-0.2 \mu \mathrm{g} / \mathrm{kg} / \mathrm{min}$ ). Transthoracic echocardiography was performed and revealed reduced left ventricle ejection fraction around $25 \%$ with akinetic apex, apical and medial segments of all walls, and all basal segments hyperkinetic (regional wall motion impairment like in taco tsubo cardiomyopathy). The laboratory tests revealed severe water-electrolyte imbalance (hypomagnesemia $0.6 \mathrm{mmol} / \mathrm{l}$ ( $\mathrm{N} \mathrm{0.66-1.07),}$ hypocalcemia $1.35 \mathrm{mmol} / \mathrm{l}(2.15-2.55 \mathrm{mmol} / \mathrm{l})$, hypo- kalemia $3.3 \mathrm{mmol} / \mathrm{l}(3.5-5.1)$ ) and profound hypothyroidism (TSH $87.3 \mu \mathrm{lU} / \mathrm{ml}$ (normal range: $0.27-4.2$ ), FT3 $0.6 \mathrm{pmol} / \mathrm{l}$ (normal range: 3.1-6.8), FT4 $3.7 \mathrm{pmol} / \mathrm{l}$ (normal range: 12-22)) with very low parathormone level (3.47 $\mathrm{pmol} / \mathrm{ml}$ (normal range: 14.9-56.9)). Cardiac necrotic marker level was not significantly elevated, without typical dynamics for acute coronary syndrome (high-sensitivity troponin 124.71-113.49 ng/l (normal range: 47.3); CM-MB 40-53 U/I (normal range: 25 ). The inflammatory parameters were slightly elevated on the $1^{\text {st }}$ day after admission (CRP $\left.9.27 \mathrm{mg} / \mathrm{l}(<5.00)\right)$ and negative from the $2^{\text {nd }}$ day, while $W B C$ were in the normal range (WBC $\left.6.5 \times 10^{3} / \mu \mathrm{l}(\mathrm{N} 4-10)\right)$. The chest X-ray did not reveal any pathology.

From admission to the Intensive Cardiac Care Unit the patient had recurrent ventricular arrythmias (ventricular tachycardia, ventricular fibrillation and torsade de pointes), hemodynamically unstable, requiring defibrillation fulfilling the criteria of electric storm.

Continuous lidocaine infusion (first $50 \mathrm{mg} / \mathrm{h}$ and then increased to $100 \mathrm{mg} / \mathrm{h}$ ) was administered and medication with QT prolongation potential was discontinued (haloperidol). According to endocrinology consultation, the patient was suspected of primary hypoparathyroidism as a consequence of thyroidectomy in the past. As a treatment, water-electrolyte (potassium, magnesium, calcium intravenously and then orally) and thyroid hormone supplementation was administered. From the $3^{\text {rd }}$ day of lidocaine infusion, no ventricular arrhythmias were detected and ST elevation fully resolved. In serially performed ECG, QT interval shortened and finally normalized (Figure 1 B). After 4 days of hospitalization norepinephrine was withdrawn, and 2 days later lidocaine was discontinued. The follow-up echocardiography revealed

\section{Corresponding author:}

Joanna Wojtasik-Bakalarz MD, PhD, Intensive Cardiac Care Unit, University Hospital, Jagiellonian University, Krakow, Poland, phone: +48 5124364 66, e-mail: joanna.u.wojtasik@gmail.com

Received: 5.05 .2020 , accepted: 22.08.2020. 
A

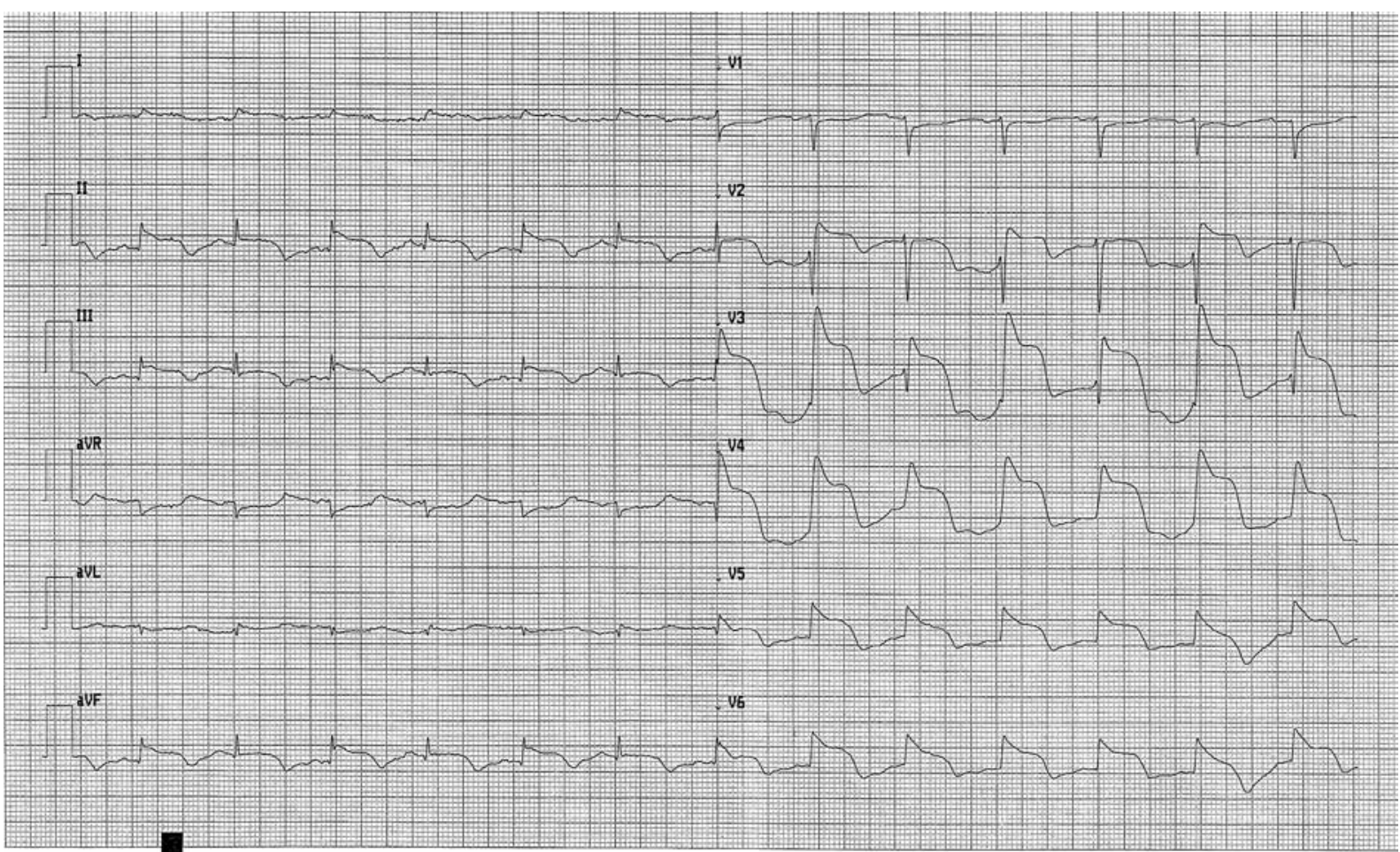

B
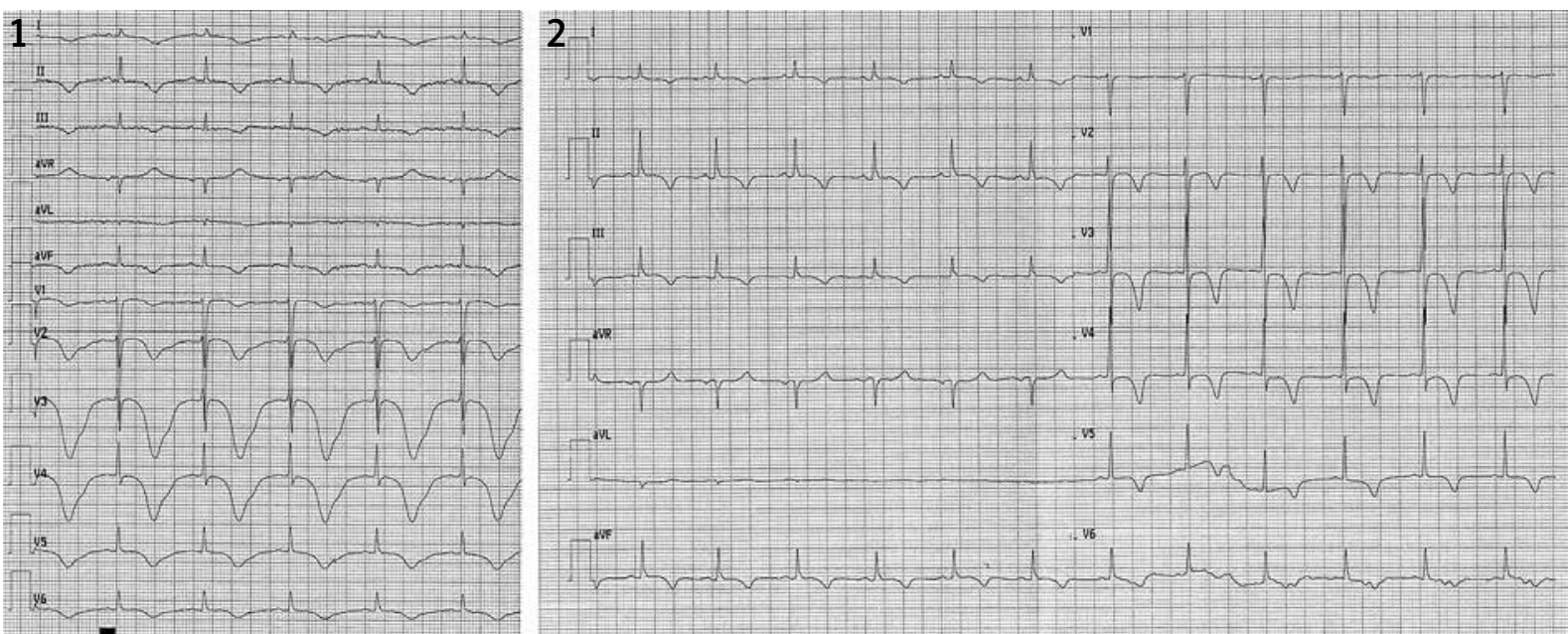

Figure 1. A - ECG at admission, with ST elevation (I, II, aVF, V2-V6) and QTc prolongation. B - Changes in ECG during hospitalization. 1 - ECG done on $3^{\text {rd }}$ day after admission. 2 - ECG done on $7^{\text {th }}$ day after admission

persistent wall motion abnormality (akinetic apex, apical and medial segments and hyperkinetic basal segments) with ejection fraction around $25-28 \%$. The patient, in good clinical condition, on aspirin, metoprolol $(3 \times 25 \mathrm{mg})$, eplerenone (25 mg), furosemide (40 mg), levothyroxine $(100 \mu \mathrm{g})$, atorvastatin $(40 \mathrm{mg})$ and potassium, magnesium, calcium supplementation, was discharged to the Cardology Department.

\section{Discussion}

QT prolongation is an established risk factor for cardiac ventricular arrhythmias of the torsade de pointes type, which may self-limit or degenerate into ventricular fibrillation and cause sudden cardiac death. There are many causes of prolonged QT intervals and acquired QT prolongation is more prevalent than the congenital form. An important risk factor for acquired long QT syndrome is use of certain cardiac and non-cardiac QT interval prolonging drugs, probably caused by gene-drug interactions [1]. Critically ill patients are especially exposed to QT interval prolongation due to comorbidities and drug interactions, which can cause prolongation of the repolarization phase. Monitoring of ECG and the QT interval is crucial in this population of patients [2]. 
Haloperidol, one of the most commonly used and well-studied neuroleptics, has been associated with QTC prolongation in the ECG $[3,4]$. Hatta et al. observed QTC prolongation after intravenous haloperidol but without ventricular tachyarrhythmia among 307 patients within a 1-year period. They focused on patients predisposed to torsade de pointes, due to other comorbidities and using haloperidol [5].

Thyroid hormones affect the cardiovascular system. Decreased expression of tri-iodothyronine in the heart cells may lead to decreased cardiac contractility, a decreasing heart rate and a slowing down of the conduction of electrical stimuli in the cardiac muscle. This may be the reason for bradycardia and prolongation of the QT interval. In electrocardiogram sinus bradycardia, low voltage of QRS complexes and prolongation of the QT interval are frequently present [6]. In the present case hypomagnesemia, hypocalcemia, and hypokalemia were probably caused by thyroid hormone deficiency, low parathormone level as well as alcohol dependency syndrome. This water-electrolyte imbalance intensified QT prolongation.

The diagnostic criteria of takotsubo cardiomyopathy [7] in this patient include the acute onset of left ventricular dysfunction, ECG abnormalities, discrete elevation of cardiac enzyme and typical echocardiographic presentation, such as apical systolic ballooning with increased contractility at the base. Additionally, angiography did not reveal any obstructive coronary artery disease. The number of cases of takotsubo cardiomyopathy has increased over the past two decades. Rarely severe hypothyroidism may have an unusual acute cardiovascular manifestation as this type of cardiomyopathy $[8,9]$. It could be explained by coronary microcirculatory dysfunction and abnormal expression of myocardial adrenergic receptors in hypothyroidism [8].

In the present case profound hypothyroidism with water-electrolyte imbalance as well as drug interaction might have been the cause of electric storm. The patient was discharged from the ICCU to the Cardiology Department with recommendation of the $\beta$-blocker dose and pharmacology for heart failure with reduced ejection fraction adjustment and echocardiographic imaging control. In case of absence of improvement of ejection fraction the patient should be evaluated for cardioverter-defibrillator implantation.

\section{Conflict of interest}

The authors declare no conflict of interest.

\section{References}

1. Van Noord C, Eijgelsheim M, Stricker BHC. Drug- and nondrug-associated QT interval prolongation. Br J Clin Pharmacol 2010; 70: 16-23.
2. Etchegoyen CV, Keller GA, Mrad S, et al. Drug-induced QT interval prolongation in the intensive care unit. Curr Clin Pharmacol 2017; 12: 210-22.

3. Blom MT, Bardai A, van Munster BC, et al. Differential changes in QTc duration during in-hospital haloperidol use. PLoS One 2011; 6: e23728.

4. Keller GA, Alvarez PA, Ponte ML, et al. Drug-induced QTc Interval prolongation: a multicenter study to detect drugs and clinical factors involved in every day practice. Curr Drug Saf 2015; 11: 86-98.

5. Hatta K, Takahashi T, Nakamura H, et al. The association between intravenous haloperidol and prolonged QT interval. J Clin Psychopharmacol 2001; 21: 257-61.

6. Shojaie M, Eshraghian A. Primary hypothyroidism presenting with Torsades de pointes type tachycardia: a case report. Cases J 2008; 1: 298.

7. Bybee KA, Kara T, Prasad A, et al. Transient left ventricular apical ballooning: a syndrome that mimics ST-segment elevation myocardial infarction. Ann Intern Med 2004; 141: 858-65.

8. Brenes-Salazar J. Takotsubo cardiomyopathy associated with severe hypothyroidism in an elderly female. Hear Views 2016; 17: 72 .

9. Micallef T, Gruppetta M, Cassar A, et al. Takotsubo cardiomyopathy and severe hypothyroidism. J Cardiovasc Med 2011; 12: 824-7. 